\title{
The role of friction stir welding tool on material flow and weld formation
}

\author{
K. Kumar, Satish V. Kailas* \\ Department of Mechanical Engineering, Indian Institute of Science, Bangalore 560012, India
}

Received 30 January 2007; received in revised form 30 July 2007; accepted 8 August 2007

\begin{abstract}
In this investigation an attempt has been made to understand the mechanism of friction stir weld formation and the role of friction stir welding tool in it. This has been done by understanding the material flow pattern in the weld produced in a special experiment, where the interaction of the friction stir welding tool with the base material is continuously increased. The results show that there are two different modes of material flow regimes involved in the friction stir weld formation; namely "pin-driven flow" and "shoulder-driven flow". These material flow regimes merge together to form a defect-free weld. The etching contrast in these regimes gives rise to onion ring pattern in friction stir welds. In addition to that based on the material flow characteristics a mechanism of weld formation is proposed.
\end{abstract}

(C) 2007 Elsevier B.V. All rights reserved.

Keywords: Friction stir welding; Material flow; Mechanism; Defects; Tool design

\section{Introduction}

The environment friendly friction stir welding (FSW) process is a potential and proven method for welding high-strength aluminium alloys. This solid-state localized thermo-mechanical joining process is predominantly used for butt and lap joints with no consumables. In general, the process is carried out by plunging a rotating FSW tool into the interface of two rigidly clamped sheets, until the shoulder touches the surface of the material being welded, and traversed along the weld line. The frictional heat and deformation heat are utilized for the bonding under the applied normal force [1]. The primary heat source is frictional heat from tool shoulder and secondary heat source is deformation heat from the tool pin [2].

The process and terminology of FSW are schematically explained in Fig. 1. The advancing side (AS) is the side where the velocity vectors of tool rotation and traverse direction are similar and the side where the velocity vectors are opposite is referred as retreating side. The process parameters are tool geometry, axial force, tool rotation speed, traverse speed and tool tilt angle. Tool tilt angle is the angle between the tool axis and the normal to the surface of the sheets being welded. Nor-

\footnotetext{
* Corresponding author. Tel.: +91 802293 2301; fax: +91 8023600648 E-mail address: satvk@mecheng.iisc.ernet.in (S.V. Kailas).
}

mally, the microstructural investigation reveals that the friction stir weldment has four different regions based on the microstructural features, namely weld nugget (WN), thermo-mechanically affected zone (TMAZ), heat-affected zone (HAZ) and base or parent material [3-6].

Tool geometry is considered to be one of the prime parameters which controls the material flow and heat input, and in turn the quality of the weld. Buffa et al. [2] numerically investigated the effect of tool pin angle on various weld zones, grain size and welding forces, and they had shown that there is a good agreement between the results of experiment and the model. The experimental work carried out by Kumar and Kailas [7] using different tool geometry explains the effect of shoulder diameter, pin diameter and pin profiles on size and location of defects, mechanical properties and final grain size. But, there is not enough conceptual background available on FSW tool design. In most of the research articles the tool geometry is not reported due to various reasons. As Mishra and Ma [8] pointed out, most of the tool design is based on intuitive concepts. The first step in deriving the concept of FSW tool design is to understand the role of tool in friction stir weld formation.

In solid-state welding, the accepted principle of weld formation is stated that the bonding occurs, when a pair of contamination-free surfaces are brought together in the range of inter-atomic-distances and the force utilized for bonding is the inter-atomic force [9]. In most of the solid-state welding 


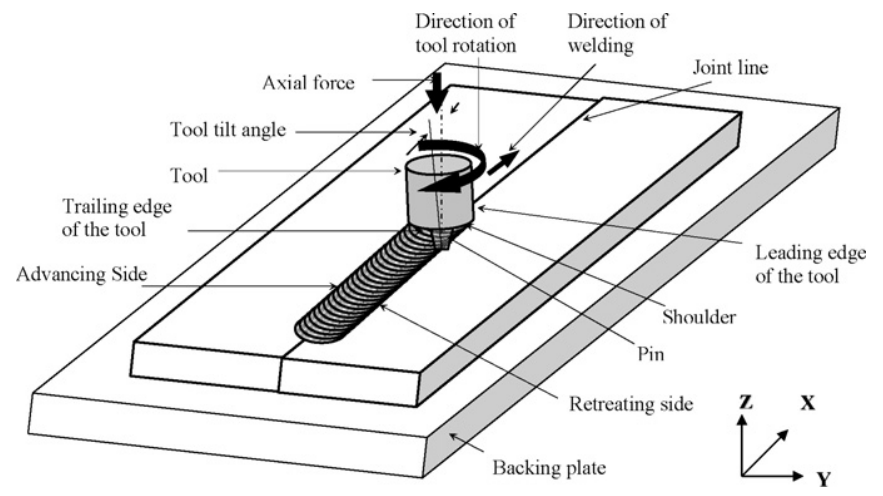

Fig. 1. Schematic of friction-stir welding process and terminology.

process, like forge welding, diffusion welding, friction welding, explosive welding, ultrasonic welding, roll bonding, etc., the bonding is established by generating fresh metal-to-metal contact by eliminating oxide layers and impurities from the interface under required pressure and temperature [10]. These process conditions modify the base material interface to satisfy the solid-state welding condition, and do not generate any additional surfaces in the material. In contrast, due to the third body (the FSW tool) interaction in FSW, additional interfaces are generated during the process. Finally, all the surfaces are coalesced with each other by the applied pressure and temperature, and thus, the sound solid-state weld is produced. Therefore, the mechanism of weld formation in FSW will be clearly known only when the role of tool is understood. The material flow analysis is an important tool to understand the role of FSW tool on the of weld formation.

There are a number of experimental studies [11-15], and computational work [16-18] has been carried out to analyze the material flow, and it is reported that the material flow in FSW is complex and it is not clearly understood. In general, the flow visualization studies have been conducted by introducing a marker material in the weld line, or by welding dissimilar materials. After welding, the marker material position is traced back by suitable means, i.e., X-ray radiography or tomography $[11,12]$ or differential etching procedure [13-15], and compared with its initial position. But, it has been said that the insertion of marker material in the weld line can alter the nature of material flow in the weld due to different material flow characteristics of the base and marker materials and introduction of additional interfaces [19]. On the other hand, the material flow in dissimilar materials of different flow properties cannot be compared with material flow in friction stir welds of similar materials. The important contribution to material flow visualization is done by Fratini et al. [20]. They incorporated the material flow and analysis with microstructural evolution.

An interesting phenomenon in friction stir welds is formation of ring pattern. This has been studied by Fratini et al. [20] and Krishnan [21]. Krishnan [21] explained the onion ring formation using a clay model. He pointed out that the formation of onion ring is a geometric effect. He stated that semicylindrical sheets of material are extruded during each rotation of the tool and cross-sectional slice through such a set of semi cylinders results in the onion ring pattern. Fratini et al. [20] explained the reason for the onion ring pattern using numerical model that the material entering from the retreating side enters the action volume and rotates at the back of the tool. But, in general, there is no experimental evidence that confirms the mechanism of onion ring formation proposed by the researchers.

The other important aspect is defect formation in friction stir welds. Kim et al. [22] and Elangovan and Balasubramanian [23] reported excessive flash formation, cavity, tunnel defect and groove like defects. And further they concluded that the defect formation is due to insufficient heat input, excessive heat input and abnormal stirring. Zang et al. [19] reported that the pore formation in a friction stir-welded magnesium alloy is due to insufficient pressure underneath the shoulder. But, there is no information available on the role of tool geometry on defect formation.

In this investigation a simple experimental method is proposed to analyze the role of friction stir welding tool on friction stir weld formation by analyzing the material flow. In this research, the material flow is analyzed without the insertion of marker material. Based on observations made in the analysis, mechanisms of friction stir weld formation, defect formation and onion ring formation are proposed.

\section{Experimental methods}

The base material used in this study is 7020-T6. Aluminium alloy 7020 is a medium strength precipitation hardenable $\mathrm{Al}-\mathrm{Zn}-\mathrm{Mg}$ alloy, which is used in aerospace industry for structural applications. The nominal chemical composition of the alloy is $\mathrm{Zn}-4.63 \mathrm{wt} . \%, \mathrm{Mg}-1.13 \mathrm{wt} . \%$, and rest aluminium. The base material dimension is $300 \mathrm{~mm} \times 75 \mathrm{~mm} \times 4.4 \mathrm{~mm}$ with square edges. The tool used in this study is $4.2 \mathrm{~mm}$ long frustum shaped pin of $6 \mathrm{~mm}$ top diameter and $4 \mathrm{~mm}$ bottom diameter with $20 \mathrm{~mm}$ diameter flat shoulder. The frustum shaped pin profile is chosen according to the self-optimized tool geometry suggested by Prado and Murr [24]. The tool material is HDS (H13), and is hardened to 55HRC. In this investigation, welding speed, tool rotation speed and backward tool tilt angle are kept constant at $80 \mathrm{~mm} / \mathrm{min}, 1400 \mathrm{rpm}$, and $2^{\circ}$, respectively. The FSW trials are carried out on a knee type vertical milling machine with square butt joint configuration.

The experiment is conducted in such a way that the tool and base material interaction is continuously increased by linearly increasing the interference between tool shoulder and the base material surface. This is done by keeping the backing plate at an angle to the weld line as shown in Fig. 2. Initially the $4.2 \mathrm{~mm}$ length tool pin is plunged $3.8 \mathrm{~mm}$, and the tool plunging reaches $4.6 \mathrm{~mm}$ by the end of the weld. In order to avoid the damage of the backing plate an aluminium support piece is kept beneath the work piece. The idea of the experiment is that the role of tool pin and shoulder on weld formation can be analyzed separately. In order to explain the effect of tool interaction on the material flow and weld formation in terms of heat input and temperature, the axial loads are measured for the corresponding tool and base material interaction. 


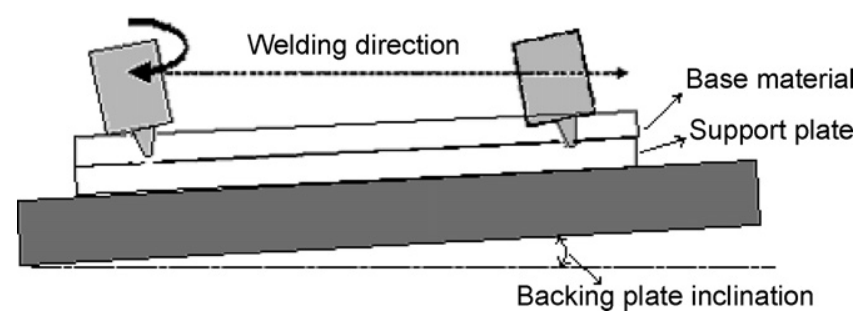

Fig. 2. Experimental details. The backing plate was kept at an angle such that the axial load can be linearly increased (from 4 to $10.9 \mathrm{kN}$ ) by linearly increasing the interference between tool and material being welded.

After welding, metallographic samples are prepared from the weld coupon at every $20 \mathrm{~mm}$ interval. Standard metallographic practice is followed, and diluted Keller's reagent is used for etching.

\section{Results and discussion}

\subsection{Material flow and weld formation}

Fig. 3 shows the cross-sections of the weld taken at various tool interference levels with the base material, with increasing axial loads. It can be seen that the defect size reduces as the tool interference increases. It can also be noticed that the axial load increases as the tool interaction increases. Above a normal load of $7.4 \mathrm{kN}$ (Fig. 3f), defects have disappeared. As Buffa et al. [2] reported, the requirement for friction stir welding process to produce a defect-free weld is by generating sufficient amount of frictional heat, thereby generating required temperature and hydrostatic pressure in the weld line. As Colegrove and Shercliff [18] explained, the shoulder is the source of frictional heat, and it prevents the material from flowing out of the weld cavity. In the present set of experiments, at the initial stages of the welding the tool shoulder is not in full contact with the base material, and hence axial load is insufficient for heat generation. The frictional heat generated in this stage is due to the interaction of the shoulder and the flash material, frictional heat generated by the interaction of the pin with the base material and heat generated due to the plastic of the deformed material. The primary reason for having defect in the weld, at the initial stages, where the axial load is less than $7.4 \mathrm{kN}$, is the lack of shoulder contact with the base material. When the shoulder contact increases with the base material the axial load increases. When the axial load is above $7.4 \mathrm{kN}$, the transferred material from the leading edge is confined in the weld cavity, and sufficient amount of friction heat and hydrostatic pressure is generated to produce a defect-free weld.

The other observation is that the weld cross-section is symmetric about the weld line until the axial load exceed the $8.1 \mathrm{kN}$ (Fig. 3a-f), and above this load the weld loses it's symmetry (Fig. 3g and h). It is evident from Fig. 3g and h that the base
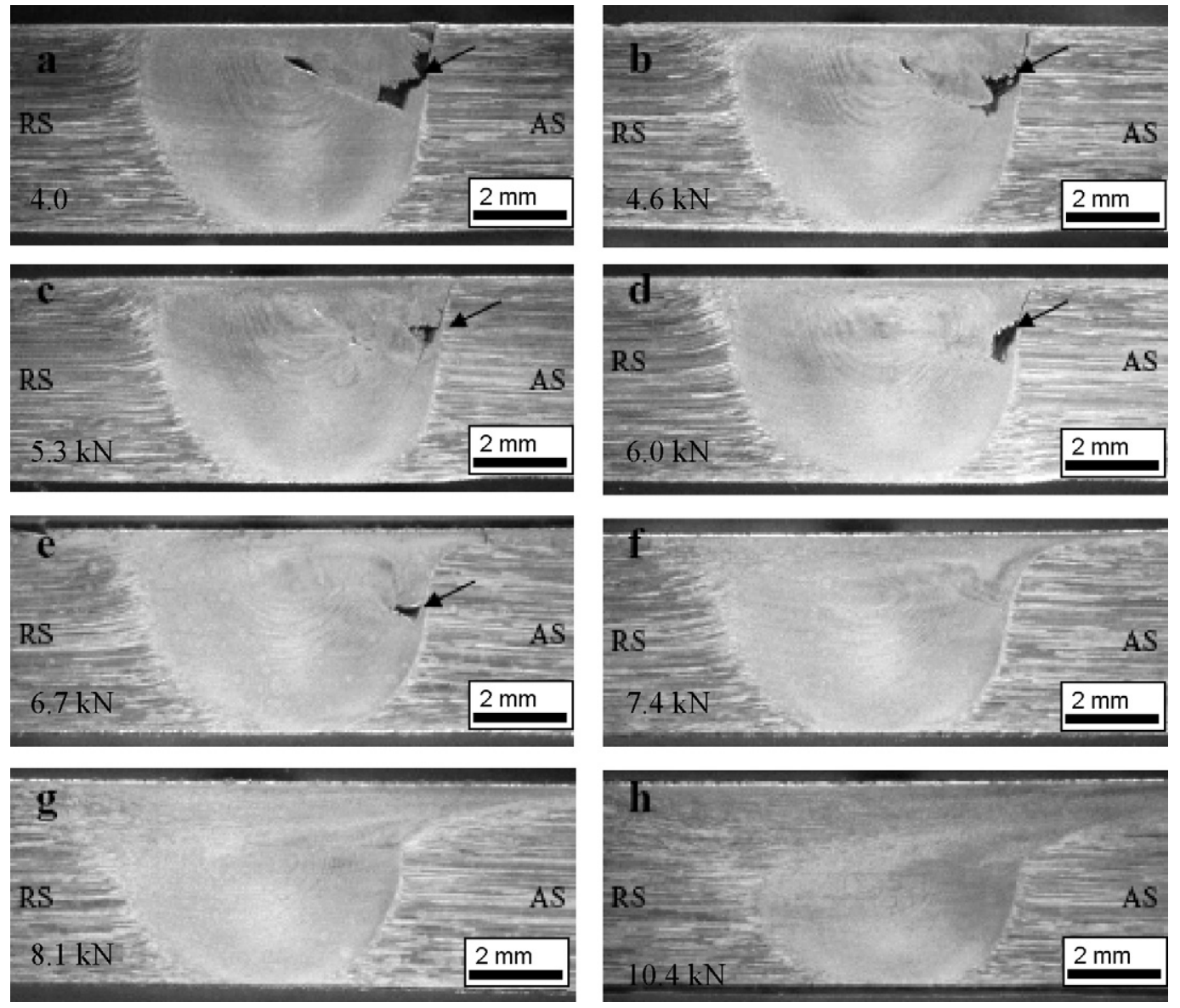

Fig. 3. Evolution of a defect-free weld as a function of the shoulder interaction with the base material. Arrow marks indicate the presence of voids in the weld. 
material loses it's symmetry because the base material from the retreating side is drawn into the weld nugget region. It can be noticed that the base material movement away from the pin can only be influenced by the shoulder. When a hard and a soft material are rubbed against each other [25] the surface and subsurface material flows in the direction of sliding and the amount of material flow is a function of contact load. Consequently, in friction stir welds, when the axial load increases above a critical value the sub-surface material flow becomes intense. Having the backward tool tilt, the contact pressure in the trailing edge of the tool is higher, and hence there is base material movement beneath the shoulder in the direction of tool rotation. The similar result has been reported by Fratini et al. that the tool rotation moves the material from retreating side to advancing side and the flux is intense at the back of the tool near the shoulder [20]. Hence, the friction stir welds are asymmetric about the weld line
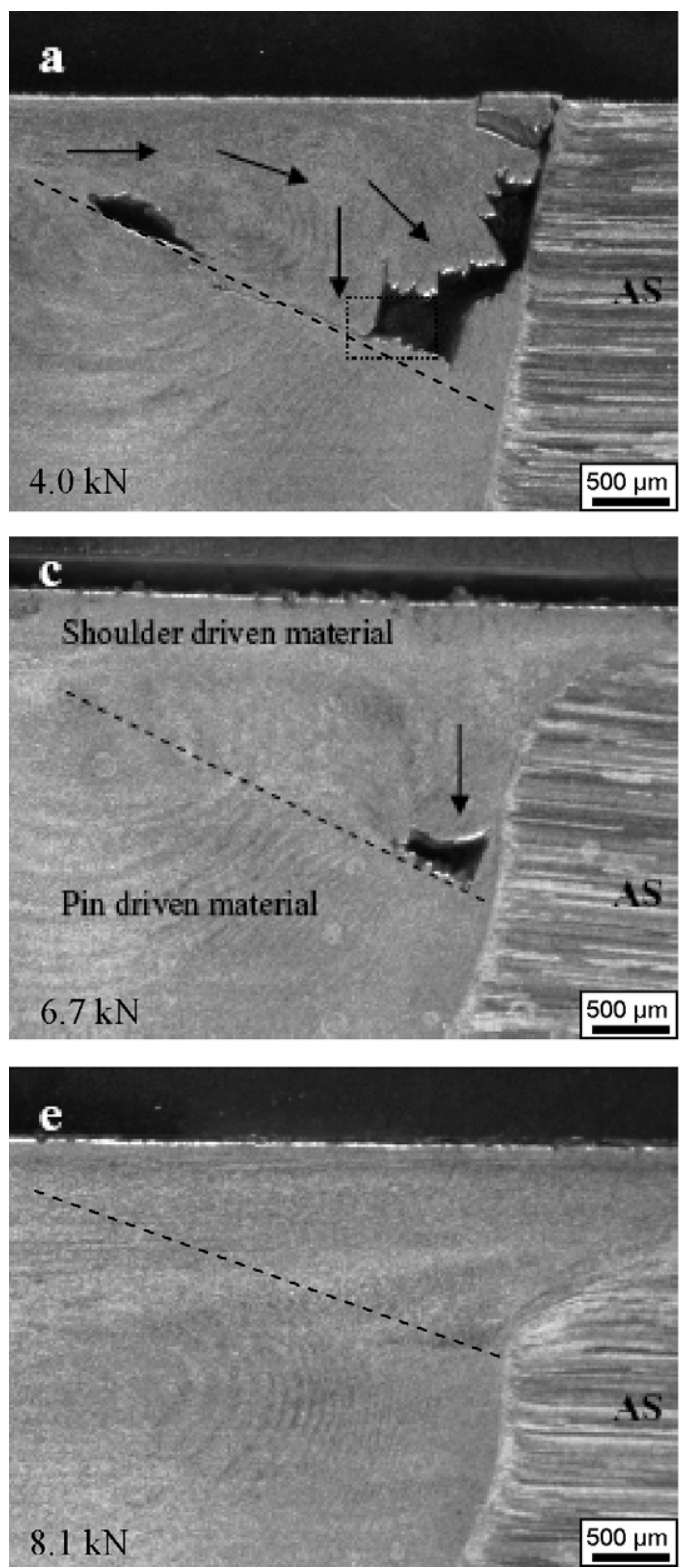

when the axial load increases above a critical value (Fig. $3 \mathrm{~g}$ and h).

The magnified views of advancing sides of the weld crosssections are shown in Fig. 4. The figures show that more material flows towards the advancing side near the shoulder as the tool shoulder and base material interaction increases due to confinement of transferred material within the weld cavity. But the material flow below certain depth in the thickness ( $Z$-axis) is not affected by the increasing interaction of the tool shoulder. It can be noticed in Fig. 4 that the material below the parting line, indicated by the dotted lines, remains unaffected by the axial load. This indicates that the flow above the parting line is influenced by the tool shoulder; while below the parting line is driven by pin alone.

The pin-driven material flow occurs during the interaction of base material with the tool pin in the weld cavity. When the
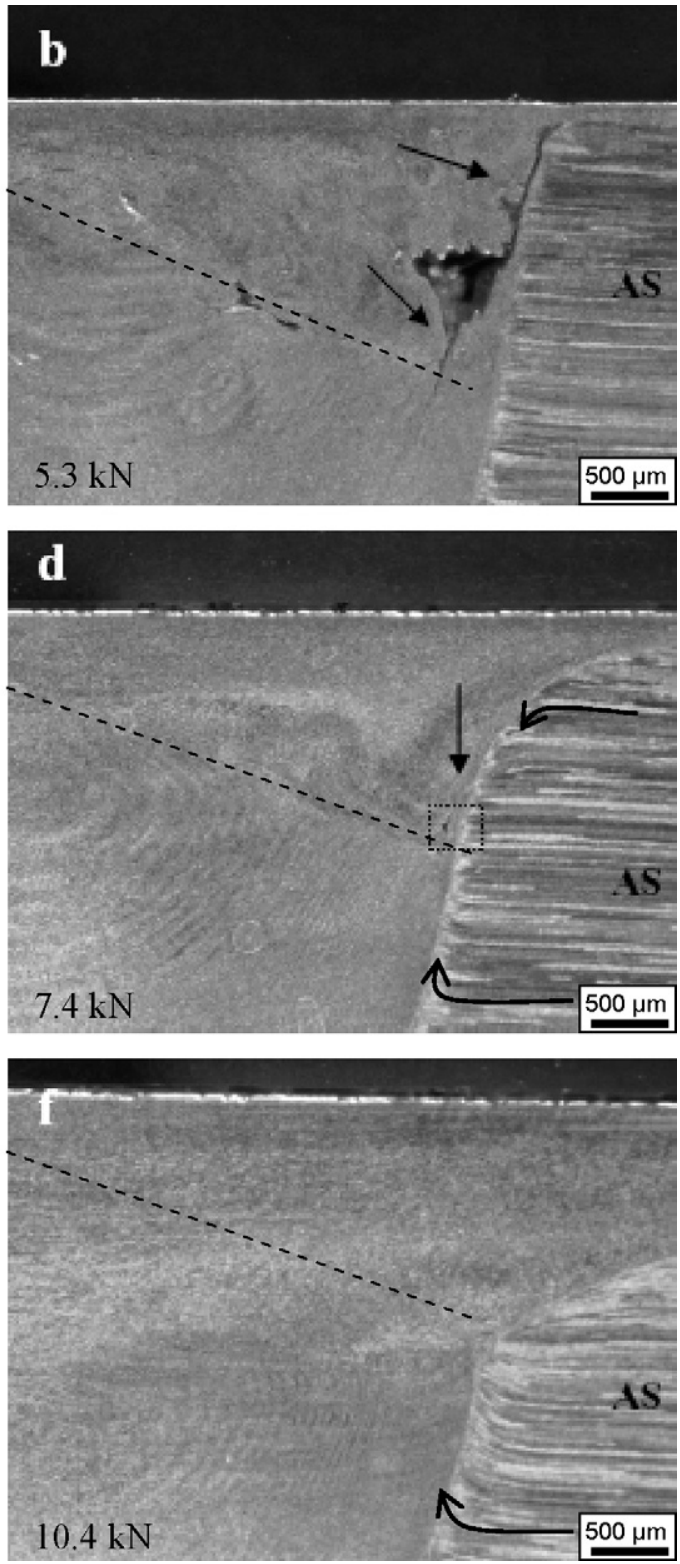

Fig. 4. Presence of pin- and shoulder-driven material flows. The arrow marks indicate the direction of material flow. The dotted parting lines indicate boundary between pin- and shoulder-driven material flow regions. Note that the relative position of pin-driven layer is unchanged. 

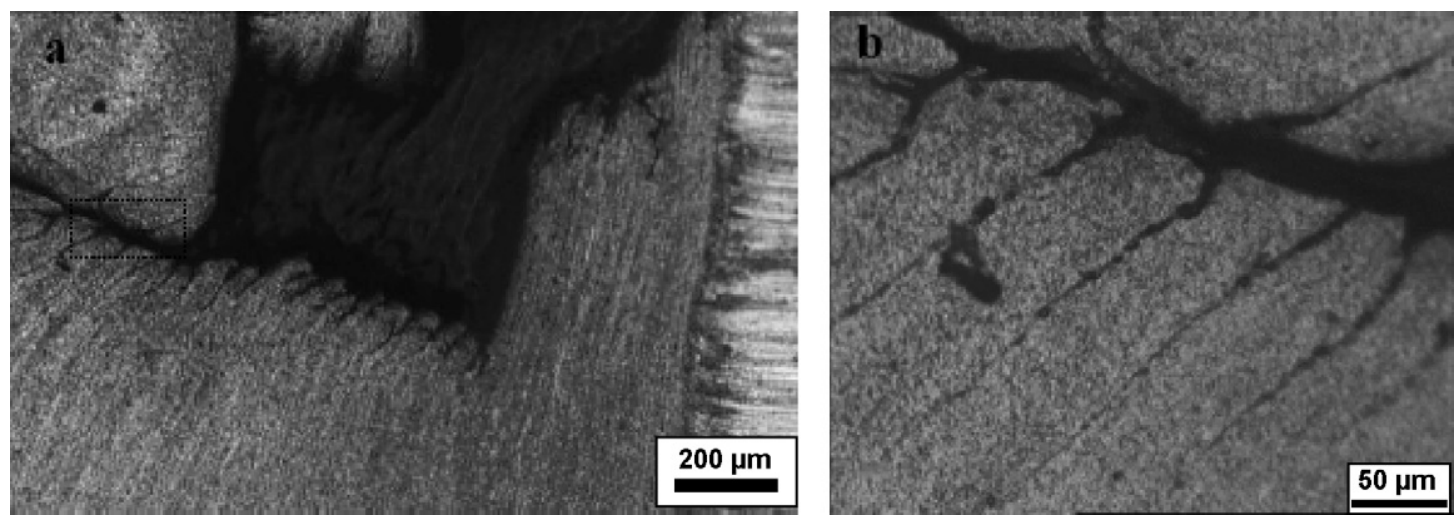

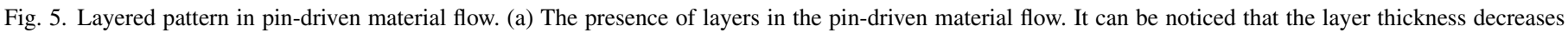
towards the side. (b) Differential etching contrast at interface between the layers.

pin is plunged into the base material, a cavity is produced. The shape of the cavity takes the replica of the outer most pin profile. When the tool is traversed, the material in the leading edge flows via retreating side to the trailing edge. During this transfer process, the plasticized material flows between the tool and the relatively cooler base material. If the resistance to the material flow between the tool and the relatively cooler base material is higher, the material will try to flow out of the weld cavity instead of reaching the advancing side. The resistance to the material flow in the retreating side depends on the width of the plasticized material around the pin and the volume of material transferred per rotation.

It can be seen from Fig. 5 that the material transfer in the pin-driven region takes place layer by layer. The layer thickness in the center of the weld is comparable with distance travelled per rotation of the tool, but decreases towards the sides (Fig. 4d). This suggests that the space created in the trailing edge of weld cavity during traversing is periodically filled. Since the pin geometry used in the study is frustum shaped, the shape of space created during traversing would be with crescentshaped cross-section with wider top and narrow bottom. As the tool advances, material from the leading edge fills the space created due to the traverse movement, and forms the stacking of layers in the welding direction as welding progresses. Since the metallographic samples show the cross-section of the weld, the section passes through several layers. At initial stages of the welding the temperature and hydrostatic pressure is insufficient to bond the layers, thus the layers are un-bonded as shown in Fig. 5. It is reported by Schmidt et al. [12] in their studies on material flow that the marker material placed in the line of weld is deposited intermittently. They proposed that cyclic deposition could be due to change in contact conditions, i.e., sticking and slipping of the tool with the base material.

Above the parting line (Fig. 4), the shoulder deflects the pin-driven material from the retreating side to advancing side (Figs. 3 and 4). The flow pattern in this region confirms that the material transfer occurs by the sliding action of tool shoulder over the pin-driven material (25). During the pin-driven material flow, due to the resistance to material flow in the retreating side, the material flows upwards. The upward movement can be seen from the base material grain flow in the retreating side (Fig. 3a-f), hence, the material that tends to escape from the weld cavity. This leads to flash formation. As the shoulder interaction increases, the material that escaped interacts more with the shoulder and is deflected back to the weld cavity.

The direction of material flow in thermo-mechanically affected zone (TMAZ), from the region adjacent to weld nugget, can be predicted from the flow direction of the elongated base material grains. From the direction of the material flow in TMAZ, the direction of material flow in the weld nugget near the TMAZ can be studied. It can also be seen from Fig. 4 that in the advancing side, above the parting line the elongated grains in the TMAZ are not disturbed until the shoulder-driven material reaches the TMAZ. From Figs. 3 and 4 it can be seen that both in advancing side and retreating side the grains in the TMAZ are bent upward in the pin-driven flow region, it indicates that in the pin-driven material flow region the material flows upward in the $Z-Y$ plane. In the shoulder-driven material region, when the shoulder-driven material reaches the advancing front the grains are bent downwards. This indicates the downward movement of material flow; this is evident from Fig. 4. This result contradicts the results reported by previous researchers [11-15], where they reported the material flows upwards in the advancing side and downwards in the retreating side. But, the upward flow of the material in front of the leading edge has been reported by London et al. [26], and the reason reported is back ward tool tilt angle which causes the plowing action. This could be the reason for upward grain flow of TMAZ in the pin-driven region. The material flow in the FSW is summarized schematically in Fig. 6.

Since the material flow in the pin-driven region is only influenced by pin, this can be described as the effectiveness of the pin to constrain the transferred material in the weld cavity. Thus, it is important that the design of the pin should be such that the maximum amount of transferred material is retained in the weld cavity. The shoulder-driven material flow can be described as the effectiveness of the shoulder to keep the material in the weld cavity. Thus, the tool shoulder should be designed such that the maximum amount of the ejected material from the weld cavity by the pin is reflected back into the weld cavity. 


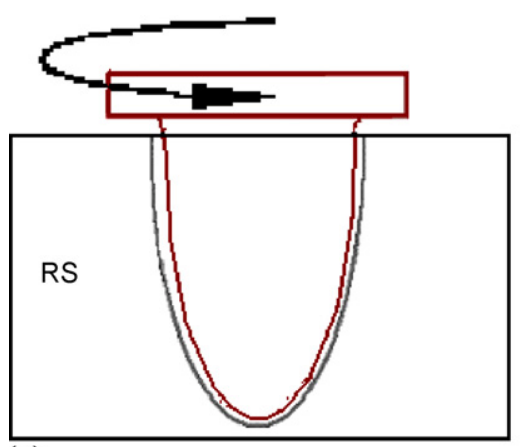

(a)

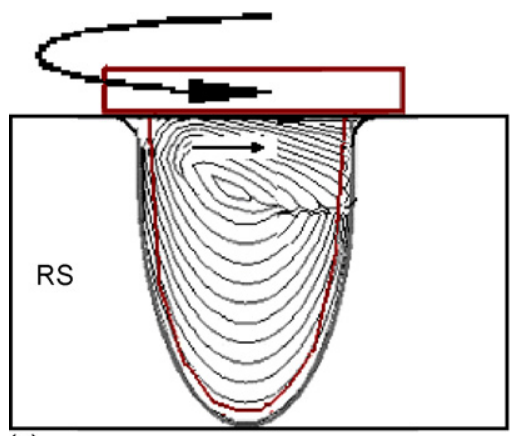

(c)

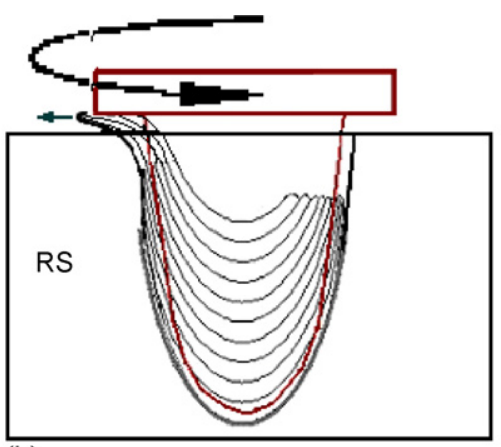

(b)

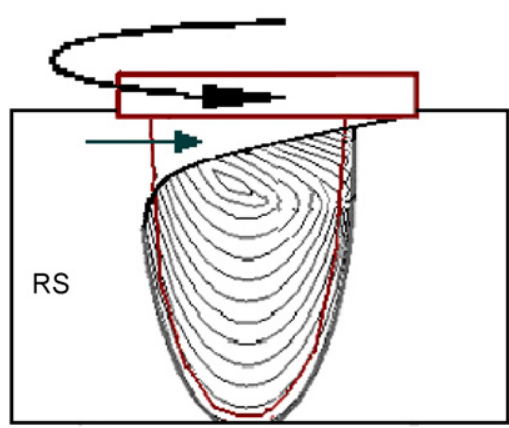

(d)

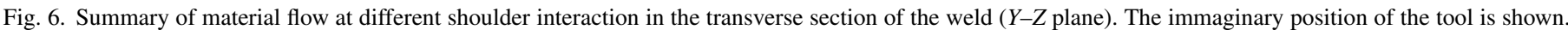

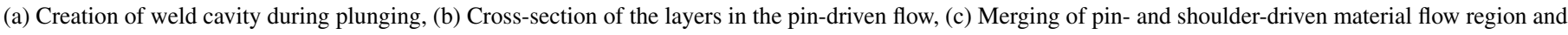
(d) Drawing of base material into weld nugget.

\subsection{Onion ring formation}

The presence of onion ring patterns in the weld can be observed from Figs. 3 and 4. The formation of onion rings can be explained from the schematic of material flow explained in Fig. 6, and the experimental evidence given in Fig. 7 proves it. The dark and light etched bands in the pin-driven material flow can be seen in Fig. 7b. It can be seen from Fig. 5a that the layers are differentially etched and appear as distinct bands. These bands form the $U$ shape in pin-driven material. As the pin-driven material interacts with the shoulder at the retreating side, it transfers from retreating side to advancing side. During this process the material carries the details of layers in the pindriven material with out changing the structure of the layers, Fig. 7a. When the shoulder interaction increases both the pinand shoulder-driven material merge with each other and the dif- ferentially etched bands join together. It can be clearly seen from Fig. $7 \mathrm{~b}$ that the complete onion ring formation is due to merging of shoulder-driven with pin-driven material flow. It is interesting to note that the ' $U$ ' shaped bands of differentially etched contrast arises from the geometric nature of stacking of layers in the pin-driven material, as Krishnan [21] proposed, where there is no circular flow in the vertical plane $(Y-Z)$. Whereas, the upper part of onion ring is made of shoulder-driven material, where there is a circular flow in the vertical plane $(Y-Z)$, as Fratini et al. [20] reported.

It is clear that the onion ring pattern arises from differential etching contrast, and the possible reason for differential etching can be explained as follows. As it is shown in Fig. 5b, the boundaries between the layers are dark etched. But, the onion rings seen in Fig. 7b do not have sharp interface as in Fig. 5b. Hence, it is clear that the layer interfaces does not give rise
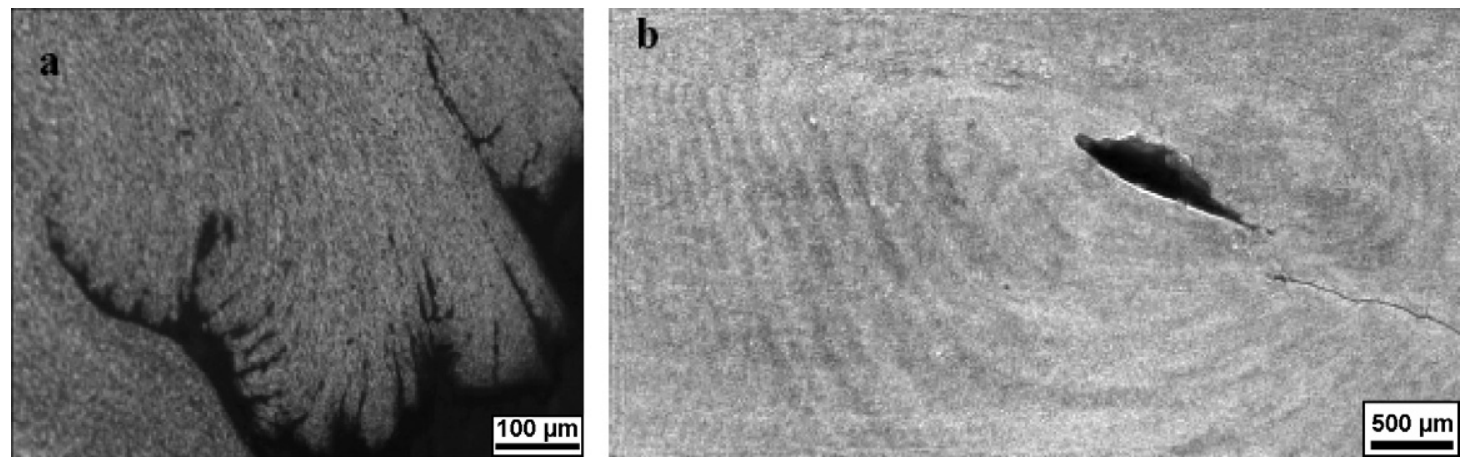

Fig. 7. Onion ring formation. (a) Differential etching contrast in shoulder-driven material and (b) Formation of a complete ring pattern. 
to etching contrast. This etching behavior can then be due to the difference in degree of deformation within the layers. The differential etching contrast due to difference in deformation is explained by Okayasu et al. [27], and he stated that the difference in stored energy leads to differential etching contrast. Since the base material 7020 is a precipitation hardenable aluminium alloy, the kinetics of precipitation and dissolution changes with amount of plastic deformation [28]. This can lead to change in concentration and size of the precipitates within the layers. Consequently, local chemical composition can be altered and can give rise to etching contrast in the transferred layers. The change in chemical composition between the bands in friction stir welds has been observed by Sutton et al. [29] for a precipitation hardenable aluminium alloy. Hence, the etching contrast arises due to the difference in degree of deformation or difference in stored energy between the layers.

\subsection{Defect formation}

As it is explained in Section 3.1, the material flow is layer wise flow in pin-driven region and bulk flow in shoulder-driven region. And, it is understood that a defect-free weld form when the shoulder-driven material merges with pin-driven material. This requires adequate temperature and hydrostatic pressure.

Figs. 3 and 4 show the presence of defect in the weld at the advancing side. It can be seen that when the shoulder-driven material does not reach the advancing side of the weld. This condition produces the groove like defect in the weld. As the axial load increases, the shoulder interaction increases, the shoulderdriven material progressively moves towards the advancing side and bonds with the advancing side base material. During this process, the material near the surface reaches the advancing side earlier and bonds with base material. The main cause for these defects is insufficient material to fill the cavity. If the shoulder is not capable of confining the transferred material with in the weld cavity, a part of the transferred material is lost as flash. Hence, the shoulder-driven material is not enough to fill the cavity and this leads to the groove and void like defects in the weld. If the weld cavity is not filled completely the required hydrostatic pressure cannot be generated. This leads to lack of bonding between the layers, and it is seen in Fig. 5b.When the shoulder interaction increases the flash material is reduced and the shoulder-driven material merges with both pin-driven material and base material. Fig. 8 is the magnified view of marked portion in Fig. $4 \mathrm{~d}$ and it shows the final filling of the weld cavity.

It is evident from Figs. 4-8 that there is a lack of bonding between the layers in pin-driven material, between shoulderdriven material and advancing side base material, and also between pin-driven layers and shoulder-driven bulk material in the welds produced with axial load of $7.4 \mathrm{kN}$ and lesser. No defects are observed in the weld produced with axial loads above $8.1 \mathrm{kN}$ for the given set of parameters. Continuous increase in tool shoulder interaction with base material increases the axial load continuously. The increase in axial load increases the temperature and the pressure in the weld nugget zone. Increase in temperature reduces the flow stress of the material and the pres-

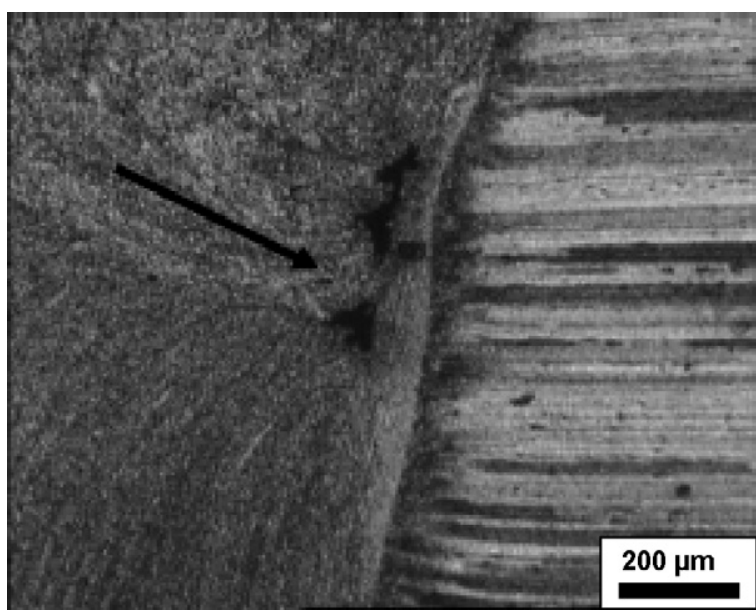

Fig. 8. Forging of shoulder-driven material against advancing side base material. The direction of material flow is indicated by an arrow mark.

sure required to consolidate the transferred material. Thus, by increasing the axial load continuously, the required temperature and hydrostatic pressure is attained at a particular axial load for a given set of parameters. As far as the precipitation hardenable aluminium alloys are concerned, lower heat input leads to better mechanical properties. On the other hand, the defects in the weld are harmful and it can deteriorate the mechanical properties. Thus, the minimum axial load in which the defect-free weld is produced could be the optimum axial load. The tensile test results of the weld at different axial loads are reported in Ref. [30]. The optimum axial load for the present set of parameters and material is identified to be $8.1 \mathrm{kN}$.

\subsection{The mechanism of friction stir weld formation}

Based on these experimental results provided from Figs. 3-8, the following mechanism of friction stir weld formation is proposed.

(a) When the tool pin is plunged into the base material a cavity is created in the base material. The shape of the cavity is decided by the pin profile. At this stage there is plasticized material around the pin and below the shoulder. The plasticized material is surrounded by cooler base material in the radial direction, tool shoulder at the top and backing plate at the bottom. This configuration, direction of tool rotation and traverse decide the material flow path.

(b) When the tool is traversed, the material from the leading edge is progressively plasticized and flows to the trailing edge through the retreating side by two different modes, namely shoulder- and pin-driven flows.

(c) The shoulder-driven material flows from the retreating side and forges against the advancing side base material. The pindriven material flows layer by layer around the pin, and the layers are stacked in the weld line.

(d) During the material transfer, if the resistance is higher for the material to transfer to the trailing edge of the tool than the material to flow out of the cavity, the flash forms. Since the material is flowing through retreating side the flash is 
formed in the retreating side. The flash formation leads to insufficient material filling in the advancing side.

(e) If the transferred material is sufficient to fill the weld cavity, at the optimum temperature and pressure the shoulder-driven material, pin-driven material and base material are getting coalesced with each other.

(f) The weld loses its symmetry, above a critical normal load because of sub-surface material flow that occurs due to the shoulder interaction with the base material.

\section{Conclusions}

In this experimental study with the help of a simple experimental procedure following conclusions are derived:

- There are two different types of material flows, namely shoulder- and pin-driven material flows. Pin transfers the material layer by layer, while the shoulder transfers the material by bulk.

- The effectiveness of the pin and the shoulder can be tested using this experimental procedure.

- Onion ring formation in the friction stir welds are due to the combined effect of geometric nature of pin-driven material flow, and vertical movement of the material due to shoulder interaction.

- For the given set of parameters the optimum axial load is found to be $8.1 \mathrm{kN}$.

- Based on the experimental result the mechanism of friction stir weld formation is proposed as follows. In FSW material flow occurs in two different modes by pin and shoulder. The shoulder-driven material forges against advancing side base material and pin-driven material, and the boundaries between the layers in the pin-driven material are eliminated.

\section{Acknowledgements}

Authors thank DRDO, ISRO/LPSC and STC/IISc for their support in terms of funding, material supply and interest towards this research.

\section{References}

[1] J. Schneider, R. Beshears, A.C. Nunes Jr., Mater. Sci. Eng. A 435-436 (2006) 297-304.
[2] G. Buffa, J. Hua, R. Shivpuri, L. Fratini, Mater. Sci. Eng. A 419 (2006) 381-388.

[3] K.V. Jata, K.K. Sankaran, J.J. Ruschau, Metall. Mater. Trans. A 31 (2000) 2181-2192.

[4] Y.S. Sato, S.H.C. Park, H. Kokawa, Metall. Mater. Trans. A 32 (2001) 3033-3042.

[5] J.-Q. Su, T.W. Nelson, R.S. Mishra, M. Mahoney, Acta Mater. 51 (2003) 713-729.

[6] Y.S. Sato, M. Urata, H. Kokawa, Metall. Mater. Trans. A 33 (2002) 625-635.

[7] K. Kumar, S.V. Kailas, in: Proceedings of the 2nd International Conference on Advances in Production and Processing of aluminium, Kingdom of Bahrain, APPA, 5-7 December, 2005, pp. III-8-1 to III-8-12.

[8] R.S. Mishra, Z.Y. Ma, Mater. Sci. Eng. R 50 (2005) 1-78.

[9] A. Oosterkamp, L.D. Oosterkamp, A. Nordeide, Weld. J. 83 (2004) $225 \mathrm{~s}-231 \mathrm{~s}$

[10] M.M. Schwartz, Metal Joining Manual, McGraw-Hill, New York, 1979.

[11] K. Colligan, Weld. J. 78 (1999) 229s-237s.

[12] H.N.B. Schmidt, T.L. Dickerson, J.H. Hattel, Acta Mater. 54 (2006) $1199-2120$

[13] M. Guerraa, C. Schmidta, J.C. McClurea, L.E. Murr, A.C. Nunesb, Mater Charact. 49 (2003) 95-101.

[14] Y. Li, L.E. Murr, J.C. McClure, Scripta Mater. 40 (2000) 1041-1046.

[15] A.P. Reynolds, Sci. Technol. Weld. Join. 5 (2000) 120-124.

[16] R. Nandan, G.G. Roy, T.J. Lienert, T. Debroy, Acta Mater. 55 (2007) 883-895.

[17] H.W. Zhang, Z. Zhang, J.T. Chen, J. Mater. Process. Technol. 183 (2007) $62-70$.

[18] P.A. Colegrove, H.R. Shercliff, J. Mater. Process. Technol. 169 (2005) 320-327.

[19] H. Zhang, S.B. Lin, L. Wu, J.C. Feng, Sh.L. Ma, Mater. Des. 27 (2006) 805-809.

[20] L. Fratini, G. Buffa, D. Palmeri, J. Hua, R. Shivpuri, J. Eng. Mater. Technol. 128 (2006) 228-235.

[21] K.N. Krishnan, Mater. Sci. Eng. A 327 (2002) 246-251.

[22] Y.G. Kim, H. Fujii, T. Tsumura, T. Komazaki, K. Nakata, Mater. Sci. Eng. A 415 (2006) 250-254.

[23] K. Elangovan, V. Balasubramanian, Mater. Sci. Eng. A 459 (2007) $7-18$.

[24] A. Prado, L.E. Murr, Scripta Mater. 45 (2001) 75-80.

[25] C.M. Nagaraj, M.Sc. thesis, Mechanical Engineering, Indian Institute of Science, Bangalore, 2004.

[26] B. London, M. Mahoney, W. Bingel, M. Calabrese, R.H. Bossi, D. Waldron, in: K.V. Jata, M.W. Mahoney, R.S. Mishra, S.L. Semiatin, T. Lienert (Eds.), Friction Stir Welding and Processing II, TMS, 2003, p. 3.

[27] M. Okayasu, Z. Wang, D.L. Chen, Mater. Sci. Technol. 25 (2005) 530-538.

[28] A. Deschamps, F. Livet, Y. Brechet, Acta Mater. 47 (1999) 281-292.

[29] M.A. Sutton, B. Yang, A.P. Reynolds, R. Taylor, Mater. Sci. Eng. A 323 (2002) 160-166.

[30] K. Kumar, S.V. Kailas, Mater. Des. 29 (2008) 791-797. 